\title{
E-morphology in Cameroon Social Media
}

\author{
CAMILLA ARUNDIE TABE \\ University of Maroua, Cameroon
}

\begin{abstract}
The aim of this paper is to examine how Cameroonians form words in social media (SM) contexts. The study explores the kind of morphological processes they adopt and the extent to which these word formation processes occur in the platforms under study (e-mail, Facebook, and Yahoo Messenger). Analysis of 230 informal e-mails and chats revealed that Cameroonians espouse and alter some of the English word formation mechanisms to suit the context of SM. The following morphological processes were found in the data: accent stylizations, clipping, borrowing, neologisms, clitics, onomatopoeia, substitution, abbreviations, compounding, conversion/inflection, reduplication, hybrid, blending, slang, and smileys. Facebook tops the lead in terms of the number and frequency of occurrence of the word formation processes, as all are found in it with some reaching $100 \%$ frequency.
\end{abstract}

Keywords: e-morphology, social media, accent stylizations, clipping, borrowing, Facebook

\section{Introduction}

The Internet is an electronic medium of communication that has led to the emergence of new communication platforms. As the technological, worldwide, and collaborative medium keeps developing, various labels have been used to refer to the language used in this medium or to lay emphasis on the particular language aspect of the technology being investigated. It is now stylish in the literature to apply words or phrases, such as "Electronic-discourse (e-discourse)" (Davis \& Brewer, 1997; Muniandy, 2003), "e-sentence" (Tabe, 2013b, p. 39), "Netspeak" (Crystal, 2006, p. 26), "Netlinguistics" (Posteguillo, 2002), "textual conversation" (Baldwin, 1996), "interactive written discourse" (Ferrara, Brunner, \& Whittemore, 1991), "Language online" (Barton \& Lee, 2013), and "Computer Mediated Communication-CMC" (Herring, 1993; 1994; 1996; 1999; 2002). Hence, the appellation electronic morphology (e-morphology) refers to the methods of word formation on these platforms.

Page, Barton, Unger, and Zappavigna (2014) defined social media (hereafter SM) as "Internet-based sites and services that promote social interaction between participants" (p. 5). KhosraviNik (2018, p. 586) used the expression "digitally facilitated spaces" while Barton and Lee (2013) employed the phrase "textually mediated online spaces" to refer to SM, for example, blogs, discussion forums, electronic mail (henceforth e-mail), Facebook (here-in-after FBK), and Yahoo Messenger (henceforward YM). The development of these social networks and the increase in the number of people using them have been influential on language use as people strive to adjust their language to suit the innovative media. Computer-mediated social platforms and cyber surfers seem to have tailored English word formation processes to reflect the electronic character of the mediums. Crystal $(2005$, p. 2 ; 2006) believed that it is a positive progress as it mirrors the power of the

CAMILLA ARUNDIE TABE, senior lecturer, Ph.D., Department of English Language and Literature, Faculty of Arts, Letters and Social Sciences, University of Maroua, Cameroon. 
creativity of a language.

Statistics gleaned from Internet World Stats Newsletter (2017) show that Africa has 388,376,491 projected Internet users with $31.2 \%$ penetration, representing $10.0 \%$ of the total world Internet users as of June 30, 2017. Cameroon is part of this Internet community. 6,128,422 Cameroonians were on the Internet with 25.0\% penetration by June 30, 2017 (see www.internetworldstats.com). Internet diffusion in Cameroon has seen an upturn of 24.5\% (2000-2017). Cameroonian FBK users as of June 30, 2017 stood at 2,100,000. In the same light, Tabe (2017, p. 67) stated that FBK is the most preferred SM in Cameroon with 35.1\% users. The Internet is gradually being used in all the peripheries of the country, especially with the creation of multi-purpose community centres in rural areas and the offer of laptops to all students of state universities by the president of the republic that began in December 2017. The increasing number of Cameroonians who connect to the Internet pilot the use of certain morphological processes and even Cameroon English (CamE) on social platforms. This has resulted in an electronic variety of such word formation mechanisms with far reaching impact on English morphology. Some Internet linguists (Baron, 2003; Crystal, 2006; Herring, 2011) believed that the context of the participants, the electronic character of the channel, the type of Computer-Mediated Communication (CMC), the size and configuration of the screen, and other physical hardware used in creating the messages are influential on the productive and receptive linguistic capacity of users. It is in this light that this study uses e-mail, FBK, and YM to investigate e-morphology in the Cameroonian SM context.

Communication through SM is prevalent among adults and especially the youths in Cameroon. From my observation and experience, many educated Cameroonians think that SM is "spoiling the language of the youths". It does not help them to form words appropriately or interact in Standard English (SE). Some critics of SM style think that the language use in these platforms contains a lot of spelling and grammatical errors, as well as colloquial expressions. Furthermore, e-mail is an asynchronous medium of communication while FBK and YM are most often synchronous modes of online communication. Though FBK and YM could sometimes be asynchronous in offline and private messages, the FBK and YM data in this study came from synchronous communication. The question therefore is: Will this divergence affect e-morphological mechanisms in the three platforms? It will be interesting to compare Cameroonians' word formation strategies in the three platforms. The aim is to find out the kind of morphological processes the users adopt, if the same morphological methods appear in the three data sets, and the extent to which each is used.

\section{Literature Review}

There is paucity of research on the language used in social media in Cameroon and the electronic variety of CamE as a whole. Within Cameroon, e-mail is seen to have expanded the stylistics of CamE in terms of format, discourse features, grammar, and politeness (Nformi, 2013; Tabe, 2004; 2008; 2011). Atud, Ambam, and Ada (2011) established that students transfer short forms and grammatical constructions they use in e-mail and cell phones to their classroom notes and essays. Research on Internet Relay Chats (IRCs) in Cameroon is seen in Tabe (2012, pp. 219-230; 2013b, pp. 39-57) who found new vocabulary and writing system as well as truncated sentences. In another study, Tabe (2013a, pp. 79-99) showed that multimedia tools can be an effective force for improving English language education in Cameroon. Anchimbe (2010, pp. 130-144) illustrated how Cameroonians living in the diaspora indirectly construct their identity in online interactions as Anglophones from the North West and South West Regions of the country. Tabe (2016) explored the forms of linguistic humour in Cameroon social media and found indicators of humour like flouting of Gricean maxims, spelling 
variations and sound devices. In addition, Tabe (2017) investigated multilingualism in Cameroon social media and found the use of English, French, Kamtok or Cameroon Pidgin English (CPE), Fran-Anglais, and mixture of languages on these media platforms.

Though studies on the language use in SM are not numerous in Cameroon, CMC e-mail and chats have proved an excellent resource to a wide range of research tasks out of the country. Researchers (Al-khatib, 2008; Brock \& Seidel, 2002; Crystal, 2006) considered Internet texts as an absolutely new genre. E-mails and chats are noted to have more structural reductions, non-standard orthography, and instances of linguistic innovation (Aslam, Ahmad, \& Sajid, 2011; Baron, 2002; Nirban, Sangwan, \& Rathore, 2011; Werry, 1996). LAN (2000) highlighted that e-mail style is dynamic and evolving; it may not directly challenge standard English, but seems likely to extend it in a variety of ways. Paolillo (1996; 2001) and Lee (2007) drew awareness to obscene language and code-switching or mixing from English to other languages in some online contexts. The implications of e-mail for learners and educators in languages in education are examined in Belisle (1996) and Nagel (1999).

Kadir, Maros, and Hamid (2012) found the the use of new word forms, structures, and style of expression in discussion forums among e-distance learning students in "Universiti Teknologi Mara" in Malaysia. Tagliamonte and Denis' (2008) analysis of Instant Message language showed the use of non-standard linguistic forms. Similarly, Farina and Lyddy (2011) found features, such as emoticons, typographic symbols, acronyms, and initialisms in text messages. They concluded that "non-standard language accounts for a minority of words in text messages, with the majority of message content following conventional forms" (p. 148). Zappavigna (2012) analyzed tweets and came to the conclusion that we are now observing a change from cyberspace conversation to "searchable talk". Petryshyn's (2014) study showed a low influx of English loan words in electronic media discourse in Ukraine. Behera and Muzaffar (2015) analyzed videos of political concern taken from YouTube using Fairclough's framework of three dimensional analyses to Critical Discourse Analysis. From their analysis, they construed that "creators of the advertising industry are very much familiar with the fact that representing and selling products or idea also mean representing and selling identities" (p. 160).

Herring (2011, p. 6) noted that digital discourse is not universal; it varies according to the context and participants. Moreover, Herring (2011, p. 4) affirmed that quite fewer studies on computer-mediated language talk about morphology. Furthermore, observations on the use of language on some Cameroonian Internet platforms (Tabe, 2011; 2012, pp. 219-230) reveal a lot of morphological creativity and modifications which, therefore, deserve greater attention and more systematic study.

\section{Data and Method}

The e-mails used here are a random selection of informal e-mails collected from 2014-2017. The FBK chats were gathered as of 2015-2017 and the YM chats were assembled from 2012-2016. Table 1 (see the Appendix) shows the corpus composition.

The FBK data came from some randomly selected Cameroonians and some Level 2 students of the Department of English in the Higher Teacher Training College (E. N. S.) of the University of Maroua in Cameroon. The students socialized on FBK and brought the hard copies of their e-chats to the lecturer. The YM data came from Level 4 students in the Departments of Administrative Techniques and Accounting in the Higher Teacher Training College for Technical Education (ENSET) in the University of Douala. Statistics from Table 1 showed that a total of 230 e-mails and e-chats constitute the primary data in this study. For ease of 
reference to the examples used in this paper, the data were coded. Those on e-mail range from E01 to E64, those on Facebook from FBK01 to FBK106, and the ones on YM from YM01 to YM60. In addition, all names on the e-mails and chats have been removed for confidentiality. The extracts used as examples are presented the way they appeared on the chats or e-mails, so some irregularities in spelling and usage are not those of the researcher.

\section{Analysis}

Cameroonians form new words in their e-mail, FBK, and YM interactions by adopting some of the English morphological processes and modifying them. The different e-morphological mechanisms that were found in the three data sets are accent stylizations, clipping, borrowing, neologisms, clitics, onomatopoeia, substitution, abbreviations, compounding, conversion/inflection, reduplication, hybrid, blending, slang, and smileys. These are presented in Table 2 (see the Appendix) with their rate of occurrences per the number of e-mails or chats.

The Table 2 indicates that 15 word formation processes were found in Cameroonian e-mails, FBK, and YM. Statistics from Table 2 showed that accent stylization is the most preferred way of forming words adopted by Cameroonians in the three Internet platforms (178 (77.4\%)), followed by clipping and borrowings which stand at $153(66.6 \%)$ and $143(62.2 \%)$ respectively. Two of the three word formation mechanisms used by a majority of Cameroonians (accent stylizations and clippings) have the common denominator that they are a retrenched way of forming or writing words. Some reasons could be advanced for the prevalence of these word formation processes. Primarily, they are a fashionable way of forming words in these Internet platforms. Another possible explanation which has also been advocated by Crystal (2006, p. 264), Nformi (2013, pp. 57-58), and Tabe (2011, p. 166) is that the reduced forms are employed for economies of time, words, money, energy and to encourage cooperation between participants. The least frequent word formation mechanism in the three data sets is smileys with a percentage of 6.6. This may be accounted for by the fact that Cameroonians are not very familiar with it. More on these e-morphological processes and the trends could be seen in the following section.

\section{Discussion}

\section{Accent Stylizations}

Accent stylization means "a word is spelled as it is pronounced in casual speech" (Lyddy, Farina, Hanney, Farrell, \& O'Neill, 2014, p. 551). Facts from Table 2 show that word formation in the three data sets is largely dominated by accent stylizations, reaching $92.5 \%$ in FBK, $79.7 \%$ in e-mail, and $48.4 \%$ in YM. This trend gives an overall picture of $77.4 \%$ which is the highest in the data. This suggests that most Cameroonians desire forming words on the social platforms under study from the way the words are pronounced in English or CamE rather than the real spellings of the words. This is an indication that the inconsistency between sound and spelling in English can be challenging for some people. The deviation from the Standard British English (SBE) spellings to CamE pronunciation structures is a new word formation mechanism aimed at not only abridging the words, but also simplifying the complicated English spelling system. This point is further strengthened by Simo Bobda (2001, p. 11), also cited in Tabe (2011), who underscored that:

A close look at these new forms shows that the native English forms which are changed are gross irregularities, features which are somewhat odd in terms of the general logic or patterning of the language, or features which may be 
perceived as unnecessary complications in the language. One can justifiably say that a common strategy in African and Asian Englishes is the "rectification" of English, in the sense that speakers of these Englishes not only regularize the language structurally, but straighten up semantic aspects which can be considered abnormal. (Tabe, 2011, p. 12)

In accordance with Simo Bobda, Cameroon cyber surfers streamline their spellings to conform to the pronunciation of the words. Examples (1)-(3) illustrate new forms of words which reflect African varieties of English or CamE sound system. The accent stylizations appear in italics with the full SBE forms in quotes beside the original versions.

(1) A: Hwws it lkewhn u went $4 d$ first medical check up? "the"

B: Bebs, dat world is very different "that"

A: Evybdyws naked $n$ mnypuzzlxquestns being asked

B: Man dnt tell me dat u stood der naked (FBK63) "that", "there"

(2) A: Ok. Goodwill told me dat he wore his own n dey nicknamed him Foo mudeca "they"

B: Yes $n$ he really looked like the chief of mudeca, so the pple were right w e name.

A: So $u$ are saying when $u$ will buy mine they will also nickname chief?

B: Ahah! Den u will not like the title? (FBK61) "then"

(3) How are u fairing ova dere, bt where are u residing now? (E13) (also ova der) "over there"

The examples above show new words or spellings like dat, dey, den, and ova dere/der which learners of English did not learnt in the past. They are synonymous to the SE words that, they, then, and over there. These words may be also heard in other varieties of English, for example, in the African-American Vernacular English in California (Ronkin \& Karn, 1999) and the Lexicon of New Orleans Terminology and Speech (see http://gumbopages.com/yatspeak.html) in which expressions like ova dere, dey, dem, em, dat, and da can be heard. In the case of Cameroon, the new words are influenced by CamE phonology where the RP (Received Pronunciation) $[\theta]$ and [ð] are simplified to $[\mathrm{t}]$ and [d] respectively, and most vowels are tense. In some other cases, silent letters are not written out and instances of these from the data are rite (right), nite (night), and noty (naughty).

The problem that may arise with this phenomenon of accent stylizations is that of misunderstanding of the words by people who do not master the context in which they are used well. Furthermore, the process produces homophones that may equally be problematic for some people. Examples include tanks/thanks, tin/thing, chart/chat, thinking/tinking. As rightly stated before, it is worthwhile for participants to learn the new words, the context, and CamE sound system so as to avoid problems of misunderstanding. The slight difficulty, notwithstanding, informal e-mail and chat platforms are breeding grounds for accent stylization; and the word formation process is held in high esteem in these contexts.

\section{Clippings/Shortenings}

Clipping is a process whereby one or more syllables of a polysyllabic word are eliminated so that the word becomes shorter (O'Grady \& De Guzman, 1997, p. 157). This definition by O'Grady and De Guzman can be modified to suit the situation of Cameroon SM. In the situation of informal e-mail, FBK, and YM, words, 
phrases, and sentences are sometimes shortened to letters (see Examples 4-6 below). Clipping is not a new word formation strategy in English, but it has been very prolific in technologically-mediated milieus, resulting to numerous innovative lexes. It is the word formation process with the second most high frequency of occurrence in the data totaling $153(66.6 \%)$. FBK tops the lead with $84 \%$ of its chats containing several clippings. YM comes next with $78.4 \%$ and e-mail has $67.2 \%$. The rate of occurrence is high in YM, but even most high in each of the FBK chats and informal e-mail in which it occurred. These Internet platforms are, therefore, fertile grounds for shortenings. Examples of clippings from the data are presented below. Consider the italicized items.

(4) A: how do you do

B: $h r$ studies gox (YM13)

The full form of $h r$ is "how are" and gox is "going".

(5) A: hw u day i was down fr all this while ... wbu

B: everything is find [sic] (FBK69)

Wbu means "what about you".

(6) A: I jst finished reax the mayor of caster bridge by Thomas Hardy We $\mathrm{r}$ treatx it under lit $\mathrm{n}$ ideas

B: ... the bor $n t$ yet born istreated [sic] under post colonial lit ... (FBK72)

The full form of $b$ o $r$ t is "beautiful ones are not".

In some cases, vowels are eliminated in some one-syllabic words, such as in tld (told), shd (should), $d n t$ (don't), and ryt (right). Some proper nouns are also shortened to make them appear new and appealing. Instances include cyn (Cynthia), Commy (Comfort), and Mday (Monday).

It was observed that Cameroonians have developed more clippings between 2013 and 2017 compared to 2005-2009. Feuba (2009, p. 30), for instance, found just $15 \%$ of shortenings which he termed "truncation" in Cameroon mobile phone SMS usage. This figure is far below those of the present study with clippings registering 66.6\% (cf. Table 2) (see also Tabe, 2011, p. 165; 2012, pp. 227-228). This implies that with time and as more Cameroonians get involved in cyber culture, clipping is being intensified in CamE and English language as a whole. It is important to note that the letter $x$ is very productive in FBK and informal e-mail contexts as it is used as a shortening for all "ing" endings. Clipping is so pervasive in Internet chat contexts that Tabe (2013b, pp. 39-50) used the expression "electronic sentences (e-sentences)" to refer to the extremely reduced written sentences of Cameroon IRC (Internet Relay Chat).

Clipping being one of the prominent word formation mechanisms in Cameroonian informal e-mails, FBK, and YM may pose a problem which is similar to the one mentioned earlier, i.e., misunderstanding to some people who are not familiar with some of the clipped forms or the context in which they are used. Johnpaul and 
Baba (2016, pp. 36-43) were in keeping with this when they observe ambiguity in "netspeak" short forms. In addition, the spelling and/or pronunciation of some of the shortened forms end up being the same with other English words and this may complicate matters for some people. For example in the data, the words too and two have as short form to. This makes the clipped form and the two other words (to/too/two) to be homophonous. Other instances of these from the data are no/know and a/and. Moreover, some authors (Atud, Ambam, \& Ada, 2011; Berman, 2006) have established that students transfer e-mail and mobile telephone short forms into their formal writings. However, it is advisable for Internet users to master the short forms and the contexts in which they are used so as to avoid misunderstandings and what Goodman (1996, p. 141) called "border crossing". Ngefac (2010, pp. 149-164) elucidated that factors like age and intimacy motivate the choice of language used by Cameroonians. The extensive use of clippings in these electronic contexts could be accounted for by the fact that university youths constitute a majority of the population from which the data were collected.

\section{Borrowing}

Generally, borrowing is the most common word formation process because all languages borrow and adapt words from other languages. In the data under study, it is the third most preferred word formation mechanism with 62.2\% (cf. Table 2). Loan words from Cameroon Pidgin English (CPE), French, and mother tongues were observed. The majority of loan words in the data are from CPE. CPE is one of the lingua francas in Cameroon (Atechi, 2011; Tabe, 2011, p. 115; 2012, p. 224). Anglophone Cameroonians use CPE to complement English "in informal settings and situations of social proximity. It is extremely common and widespread" (Schneider, 2008, pp. 297-298). Borrowed nominal elements from CPE occur with a high frequency in the FBK data (100\%) than in the e-mail (35.9\%) and YM (23.4\%) materials. This could be that some participants are identifying themselves with what is done in their society. Examples (7)-(8) show the use of CPE in the data. CPE words and phrases are italicized.

(7) A: not as easy as u think i am still new in dla

B: ok..... ashia (YM25)

The social concept behind ashia does not exist in English. However, "courage" could be considered as the Standard English rendition of ashia.

(8) B: dear can u immagine [sic] that im still pregnant
A: so early baby
B: na mistakeoooooooooooooo (FBK58)

The equivalent of the CPE item above is "it is a mistake". This example shows that mistakes exist in both languages (CPE and English) and many words in CPE come from English.

Other expressions used in CPE (and in other home languages) that were found in the data like fufu (cassava or corn paste), bobolo (a kind of hard paste produced from cassava), garri (made from cassava), and njangi (thrift and loan) are evocative of some of the cultural practices in the country. Moreover, they render the English used by Cameroonians in these Internet platforms indigenous. Tabe (2011, p. 116) rightly thought that the use of expressions from CPE is proof of the background knowledge or culture that participants share. This 
makes borrowings from CPE peculiar because the language is not spoken elsewhere.

Borrowed Nominal elements from French were also found in the Internet interactions of Cameroonians. French and English are the official languages in Cameroon. Biloa (2004) accentuated that there is no indigenous language in Cameroon that possesses many speakers as the French language. The total frequency of occurrence of French loans in the data stands at $14.4 \%$. The platform with the highest rate of French words is FBK with 24.6\%, while e-mail and YM have $4.7 \%$ and $6.7 \%$ respectively. In general, there is a low occurrence of French in the data. This stumpy frequency of French is similar to the findings of Tabe (2017) who found just $1 \%$ of French expressions in some other SM data in Cameroon. This pointed to the fact that though Cameroonians use French and English as official languages, they are careful not to mix the two in certain communication situations. The excerpts below illustrate the use of loan expressions from French. Consider the italicized items.

(9) A: I stopped at rond point Melong and call your mom to come and take your dad's medicine...its not all about you and I and the kids, there is tonton Ema, tata. So, the large family in Kongsaba, my large familly from big pa'a in bamenda and all you... (FBK58)

The English rendition of rond point Melong is "the roundabout at Melong". The SE equivalent of tonton is "uncle" while tata means "aunt/auntie".

(10) B: ... he is normore [sic] in dschang he succeeded one concour in Kumba A: thats fantastic which concour is that; (FBK8)

Concour means "competitive entrance examination".

The words in italics above show that some Cameroonians form words in SM contexts by borrowing from French. This is proof of the flexible nature of Cameroonians as they are able to easily transfer what goes on in their society to the Internet platform.

Loans from home languages were equally detected in the data. Recent research put the individual languages of Cameroon at 284 with 279 known to be living languages (Ethnologue, 2017). Some of the languages like Fulfulde, Beti, and Duala are widely spoken by people. Most people learn and speak the native languages that are widely used in the region in which they find themselves, and this is evident in the kind of loan words found in the data. Some of the FBK chats which were collected from students in Maroua, for example, had expressions from "Fulfulde" which is the local language widely spoken in Maroua although many of the students do not originate from the region. People do this to facilitate their communication with the native population. Data show that the frequency of borrowed nominal elements from home languages is low. Only 20 (13.1\%) e-mails and chats had words from indigenous languages, with FBK having the highest (18.9\%) followed by e-mail (12.5\%) and YM the least (3.4\%). This low occurrence could be attributed to the fact that nowadays many youths turn to abandon the use of indigenous languages in favour of English and French, so that they can have a comfortable social status in the society. Below are some instances of the use of loan words from home languages (see the italicized expressions).

(11) A: U re back again sis are u through with ur class

B: assalamualaikum... (FBK60) 
Assalamualaikum (also salamalakoing) is from the Fulfulde and Arabic languages and it means "peace be upon you". It is a salutation which is used when you wish to enter a person's compound for a visit. In the context of FBK above, it shows the willingness of the addresser to chat with the addressee.

(12) B: what abt clichi?

A: you jst need to be specific abt de type of loin yu need. (FBK72)

Clichi is also from the Fulfulde language. It is a kind of meat that has been seasoned with groundnut paste and dried well, so that it can be preserved for as long as possible. It is usually eaten in the dried state.

(13) B: I propose that u send money 4 me to buy gandula that really fits you ...

A: how much can they sell that ngandora? (FBK61)

Gandula (also spelt as ngandora or gandoura) is equally from Fulfulde. It is a big, long, loose gown worn by men.

The words italicized above are an indicator of Cameroon's cultural values. These and most of the other borrowed words from indigenous languages found in the data come from some of the languages classified by Kouega and Somb Lingom (2013, p. 20) as "majority minority languages". Although some of the data were collected from students who are learning English in the university, loans from native languages were still found because the participants wish to identify themselves with their cultural and geographical setting. Cameroon e-mail, FBK, and YM are an amalgam of CamE, CPE, French, and many home languages resulting to a multilingual Internet lingo that reflects the multilingual nature of the country (see Tabe, 2017). The borrowed nominal elements from native languages are unique to Cameroon because some of the languages from which Cameroonian Internet users borrow words from are specific to Cameroon. They contribute in bringing out the indigenous nature of the English spoken or written in Cameroon. Hale and Scanlon (1999, p. 21) and Crystal (2006, p. 81) have supported this when they stated that writing English from the British or American viewpoint in this digital era is completely obsolete. They thought that people should not be xenophobic; they should be cosmopolitan and enjoy the best of other cultures and tongues. The linguists (Hale \& Scanlon, 1999, p. 9; Crystal, 2006, p. 80) believed that Internet populace is made up of comparatively small groups who have their own culture or identity and behaviour and will share a certain background and style. Hence, they recommended cyber surfers to consider their context and display their sub-cultural literacy when they are online.

\section{Neologisms}

Neologism is a new word or expression, or a new meaning for an existing word. It can be observed from Table 2 that the general percentage of neologisms in the three data sets is $51.8 \%$. It is the fourth most favoured word formation process in the data. The table equally discloses that the use of new terms in FBK is high (84\%) compared to YM (66.7\%) and e-mail (25\%). The new words have been added into the English language due to the invention of the Internet and its social networks. The italicized items in the excerpts below are examples of words that have become prevalent with the advent of Internet and SM.

(14) ... try to come with those materials and the USB flash for that person is really expecting it. (E36) 
USB flash or key is a computer device that is used for storing data and can be used on extra gadgets like radios and digital cameras.

(15) A: i just hope that with this hussling $\mathrm{u}$ dont fall into temptations ...

$\mathrm{B}$ : you're rigth the cyber is closing

I have to say good night. (FBK58)

Cyber highlighted above is a variant for "cyber cafe" in the context in which it appears; it stands for a room where people can pay to use the Internet. In addition, cyber can be also used as a prefix relating to computers, especially the Internet, for example, cyber crime. Crystal (2006, p. 23) and Posteguillo (2002, p. 26) underscored that some prefixes that came about as a consequence of the Internet have turned out to be among the most useful in English language (e.g., $e$ - in words like e-commerce and e-money; web in terms such as website and webmaster). This has made the Internet invariable in the production of new terms. Additional new expressions discovered in the data include logging out, download, browsing, web, google search.

Another dimension of neologisms found in the data is superficial lexical changes or "semantic shift" (Herring, 2011, p. 4). New meanings have been adapted to some words to suit the setting of computer and the Internet. These are contextualized below. The fresh meanings of the italicized items are given below the extracts.

(16) B: the connection is worst here

i think am going home in few mins. (FBK62)

Connection: It is the technical possibility (the medium which is independent of those who communicate) for two or more people to communicate with one another by Internet.

(17) B: What a coincident; can you made [sic] me a photograph attachment

A: Nest [sic] time. I do not have much time. Bye. (YM5)

Attachment: It comes into view on an e-mail message like a paper-clip to indicate that other files (e.g., pictures, music, and lectures) have been joined to the message.

(18) A: it a pleasure meeting you online. i want to specially thank you for your post on voice of the unborn. am determine to fight and end this act. everyday if a baby is safe because our postings then it will be a great a step of change.

$\ldots$

B: hey, you are so good on chats i like to chat with you all times. (FBK57)

Online: on the internet; post: to send messages or contributions by Internet; chats/chat: "real time" text conversation(s) between two or more Internet users.

Other expressions with semantic changes that were discovered in the data include sign out/signing off, hacked. Many new words are created regularly on the Internet as the technology keeps developing. 


\section{Cliticization or Contraction}

Cliticization or contraction is the shortened form of a word or a combination of words which is often used instead of the full form in informal situations. An apostrophe is often used to indicate omission of some portions of the word(s). Clitics must be attached to another word in a sentence. Data portray that contraction is the fifth most preferred way of forming words by Cameroonians (44.8\%) after accent stylizations, clippings, borrowings, and neologisms. It occurs with a high frequency in FBK (60\%) compared to YM (50\%) and e-mail $(43.8 \%)$. Examples of contractions in the data are provided below.

(19) A: if you don't mind I won't answer that question

B: I dont mind

B: $i^{\prime} l l$ do the provissions [sic] $4 \mathrm{u}$ thats what $\mathrm{i}$ want 2 share with $\mathrm{u}$

A: $i$ ' $m$ sorry i already love someone else you don't have a place. (FBK64)

"Do not", "will not", "I will", "I am" are the full forms of the contractions italicized above. The use of contractions like other shortened forms of words is aimed at reducing time and effort in typing.

\section{Onomatopoeia}

Onomatopoeia is the creation and use of words which include sounds that are similar to the noises that the words refer to. Information from Table 2 depicts that the percentages of onomatopoeia in the data are 10.9, 48.2, and 46.7 respectively in e-mail, FBK, and YM. The general percentage is 37.4. The occurrence is neither high nor frequent in the e-mails or chats in which it occurs. Some onomatopoeic words that were identified in the data have been italicized in the excerpts below.

(20) A: ... click on that link

B: I zill [sic] not do that the connection is very sloz [sic]

A: that is the photos link click it you will see the photo (FBK62)

Click is a word that repeats the sound. It occurs when the computer device known as a mouse is pressed on the right or left part of it and the action produces a "click" sound - a short sharp sound.

(21) Hahahahahahahahahahah. How abt wat u told me of? And b4 I 4forget u knw say my mum is back frm de village? baaaaaaaaaaaaaaaaaaaabs guest [sic] wat she Brought; clay pan. (E45)

The onomatopoeic expressions above indicate laughter or friendly emotions and exclamation. Similar words detected in the corpus included Waooooo!, Boum!, waow, жееееееееееееееееееееееееееееееееееееееее , chaiiii, dunno, Hooo!, ehhhhh. These examples are similar to those of Feuba (2009, p. 32) and Tabe (2012, p. 226) in their analysis of Cameroonian SMS texts and IRC respectively. 


\title{
Substitution of Numbers for Letters
}

The use of numbers instead of words was recurrent in the data under study. The general rate of this kind of replacement in the data under study stands at 32.6\%. Table 2 also reveals that the specific percentages for e-mail, FBK, and YM are 37.5, 41.4, and 33.4 respectively with the frequency of occurrence being high in each e-mail and FBK chat in which it was detected. Though the rate of changing over numbers for words is low, it is still significant because it is one of the word formation processes that have emerged with the advent of the Internet and its social platforms. The replacement of numbers for words is exemplified in the extracts below.

(22) pls bro, I am really down and will be happy if u send me an 8081 . (E19)

8081 stands for "assistance" in the Cameroonian context.

(23) B: u flatter me and i like ur determination. thank u 4 ur understanding ... (FBK58)

4 has been used to replace "for".

(24) B: how is your younger sistershusbqnd [sic] hope dox fine 2

B: please don't take it 2 hard on me

A: no problem speak your mind. (FBK64)

2 has been substituted for "too".

The problem with this kind of word formation process as can be observed from the examples is that one number may stand for different words and this can lead to comprehension problems if the context is not taken into consideration. For instance, 1 could stand for a number or a pronoun; 2 could mean "to" or "too" and 4 can imply "for" or "four". It is in this light that the expression "number homophones" can be employed to refer to this method of word formation because the numbers and the words they represent are similar in sound. Such novelties are used to signify and maintain online communities.

\begin{abstract}
Abbreviations
Abbreviation is the process of leaving out one or some parts of words so that the word or phrase becomes shorter, thus a new word is formed. A total of $64(27.9 \%)$ e-mails and chats contained some abbreviations. There are two types of abbreviations that were discernible from the data, namely, initialisms and acronyms. Initialization is a type of abbreviation formed by using the first letters of words and read by spelling each letter. The total number of initializations in the data is $36(15.7 \%)$. The rate of occurrence is very low with e-mail having just 4 (6.3\%), FBK 20 (26.7\%), and YM 12 (20\%). This low occurrence could be attributed to the fact that participants prefer other new and latest word formation techniques to older ones like initialisms in online social interactions. The italicized items in the excerpts below are examples of initialization found in the data.
\end{abstract}

(25) A: why did u abandone $U B$

B: i only suspend [sic]. (FBK35) 
The full meaning of $U B$ is "University of Buea".

(26) Well sis life is not easy here in the $U S$. (E37) (also U. S. A)

$U S$ or U. S. A stands for "United States" or "United States of America".

Acronyms were also observed in the data. They are formed by taking the initial letters of each word in the name of something (e.g., a title) and pronouncing or reading it as a word. The frequency of acronyms in the data is even lower than that of initializations. They occur only in FBK and YM with 20\% and 21.7\% respectively giving an overall percentage of 12.2. An instance of acronym is presented below in italics.

(27) A: nothing bad but only stress one is going through in ENSET

B: what are u doing ENSET. (YM24)

ENSET: Ecole Normale Supérieur de l'Enseignement Technique (Higher Teacher Training College for Technical Education). As rightly stated earlier, technological revolution has also brought about language evolution and modern citizens turn to abandon the long-established ways of forming words especially when they are communicating on social platforms.

\section{Compounding}

Compounds are lexemes composed of two or more free forms. A total of 43 (18.7\%) compounds were discernible in the data. E-mail had 15 (23.5\%), FBK 20 (18.9\%), and YM 8 (13.4\%). The figures show that compounding appears not to be prominent. Nevertheless, the frequency is low because focus was mostly on new compound words (neologisms). Most of the compounds found in the data were either fused or written as two separate words. Hyphenated compounds were rare. Examples of some compounds that were recognized in the data are as follows:

(1) Facebook derived from two nouns ("face" and "book") and it denotes a website where you can show information about yourself and communicate with group of friends.

(2) Sign out derived from a verb ("sign") and a preposition ("out"). In the context of Internet, it means to stop surfing.

The examples show that a word can belong to different morphological strategies. The cases seen above could be also neologisms and sources of derivation.

\section{Conversion and Inflection}

Conversion is the process of forming words without changing the base form. The word is simply altered from one part of speech to another. In other words, there is a change in the class and meaning when it is derived. Haspelmath and Sims (2010, pp. 39-40) gave some examples: walk (noun)—walk (verb), plant (noun)—plant (verb). O'Grady and De Guzman (1997, p. 157) referred to conversation as "zero derivation" since no affixes are added to the base form to create a new word. With derivational morphology, new words are derived. Derivational morphemes are added to produce new words that are derived from the root word. For example, examine (verb) - examination (noun), beauty (noun)—beautiful (adjective)-beautifully (adverb), market (noun) - supermarket (noun). The meaning of the derived word is not the same as the root and the word class may change with each derivation, though not always. Inflection, on the other hand, is the process by which 
inflectional morphemes are attached to words and this allows speakers to morphologically encode grammatical information. The difference between derivation and inflection is that inflection inserts additional letters to a word to change its grammatical function (e.g., turning "rationalize" into "rationalizing" or "rationalized", "girl" into "girls"). Here the word class does not change. Derivation uses an existing word to form a new word whose meaning derivates from and away from the original meaning (e.g., turning "national" into "international" or "nationality"). For more fine distinction between inflection and derivation, see Haspelmath and Sims (2010, pp. 81-113).

Conversion and inflection are methods of word formation that have been very prolific in English language (Internet English inclusive). However, in this study emphasis was placed on the new words that are increasingly making their way into the English language through the Internet, to see if users have transferred their skills of conversion and inflection to create or produce new words or meanings from Internet register. It is for this reason that the frequency of occurrence is low (14.4\%). In the e-mail data, $3(4.7 \%)$ new words were found to have changed their classes or meaning; FBK had 20 (26.7\%) and YM 10 (16.7\%). An example of conversion is the italicized item below.

(28) A: hey this is ma new FB username, so pliz search and add me B: wassup bro. (FBK25)

In the case above, $F B$ is the abbreviation for "Facebook" and a new meaning has been derived from it because it is used as an adjective that modifies username, not the original noun that we know. Other productivities for "Facebook" and "chat" are given in Table 3 (see the Appendix). Examples of inflection are shown below.

(29) Judith e-mailed me that you replied her letter. (E09)

Here, "ed" has been added to "e-mail" to form e-mailed which is the past tense form. Other creativities for "e-mail" are given in Table 3.

(30) B: ... Am chatting from my small office along the Com.

Avenue where I study and prepare conference papers

A: ok my own number is ... (YM21)

Chatting (also chattx) is the present continuous form that has been formed from "chat" and "ing". Other variants of the word were equally found in the data and are presented in Table 3. Other inflections discovered include the following:

School schooling schooled

Bicycle bicycling

The Table 3 presents additional lexical productivities that were found for some Internet-related words.

Information from Table 3 discloses e-mail as a verb in the past form (e-mailed) and a modifier/adjective (e.g., e-mail address). Facebook is used as an adjective (e.g., facebook stuff); chat occurs as a verb in different forms (infinitive, present participle, past tense) and a noun. Furthermore, verbs of different forms are equally 
produced from post (infinitive, future, and past tense). The ability to convert one class of word into another class or to change the grammatical function of a word is a sign of the flexibility of English. Renouf (2007) has acceptably stated that "the degree of frequency, productivity, and creativity indicate how active and important a word is in the language at a given point in time ..." (p. 61). It is hoped that Cameroonians will come up with more lexical productivity from Internet-related words as they make progresses in the use of the technology.

\section{Reduplication}

Reduplication is the recurrence of a word more than once. The total frequency of it in the data stands at $13.5 \%$ with e-mail containing just 3 (4.7\%), FBK 20 (26.7\%), and YM 8 (13.4\%). This low occurrence stems from the fact that many Cameroonians are being attentive not to blemish their writings with copious repetition. Two types of reduplication were observed in the data: the complete repetition of all the base or clipped form of a word and the special repetition of letters in a word for special effects. Consider the excerpts below which illustrate repetition of base or clipped form of words (the italicized items).

\section{(31) B: JUST THT I LOST MY SIS}

\section{A: sorry bro}

i'm so sorry for that

i was really hurt. (FBK59)

(32) A: i am using a phone its difficult with a phone i am on a blackberry phone so its impossible nless i go to a cyber cafe

B: ok but what i needed was just about 2 pages. (FBK3)

The examples of recurrence above are utilized for emphasis, cohesiveness in the texts, and solidarity with participants. The special repetition of letters became fashionable with the development of social platforms like e-mail and FBK. It was more prevalent in the data than the repetition of words. Below are some examples.

(33) A: Grand sis you will not accept my request?

B: helloooooooooooooooooooooooooooooooooo

A: helllooooooooooooooooooooooooooooooooooooooooooooooooooooooooooooooooooo grand frère. (FBK29)

(34) B: accept greetings too from anastasia and chao

A: oooooooooooooooooooooooooohnooooooooooooooooowhats up with ma girl

B: she is fineeеeeeeeeeeeee

A: ooooooooooooooooohiseeeeeeeeee. Say ma love to her okkkkkkkkkkkk

B: i will ohhhhhhh. (FBK77)

The special repetition of letters is employed by participants for emphasis, camaraderie, cooperation, and humour. Other instances of such reproduction of letters include nooo, verrrry, dooooooooooo. 


\section{Hybrid}

This category of words is formed from two or three different types of word formation techniques. We have words that are a hybrid mix of numbers and letters and those that are a word-number-clipping hybrid. Facts from Table 2 unveil that the total rate of hybrid in the three data is very low (12.2\%). A Close look at the table also divulges e-mail having 17.2\%, FBK 14.2\%, and YM 3.4\%. Although the rate is low, the frequency of occurrence in each of the e-mails that it occurred is high. This shows that some participants are more creative or prone to some word formation methods than others. They do this not only to play with language, but for cooperation and friendliness with their addressees. Consider the italicized items in the extracts below which illustrate hybrid of numbers and letters.

(35) A: I might be free 2 moro

B: ok we might see

A: I hpeull go to church 2moro (also 2morrow). (YM9)

"Tomorrow" is the full meaning of the italicized items.

(36) B: okay, i will try to get in contact with her ...

A: she is fine

... wen u get through to her ex10 my salut to her please. (FBK7)

Ex10 stands for "extend". Other examples of words composed of letters and numbers observed in the data include everyl, some1, 4ever, 4get, 4got, 4rm, 2day, in2, 2be, 2geda, k6 (kiss), big k66sss, dere4, and gr8t/grt/gr8.

Hybrid of word, number, and short form was infrequent in the data. An example is given below.

(37) A: if you say so but i don't see it too important for me

B: i had wish we talk it face 2 fce but then.... let just. (FBK64)

Face 2 fce stands for "face-to-face".

The examples symbolize a lighthearted communication style. This type of pattern of word development could be geared at demonstrating that the Internet is not only a technological development, but has also led to language growth or expansion. This is in consonant with one of the principles given by Hale and Scanlon (1999, p. 9) which is also cited in Crystal (2006, p. 80) that the individual ought to invent, create, and play with the language "in the form of new words and odd constructions...". It is hoped that more hybrids and other new word formation processes will come up as the Internet keeps developing at a fast rate and more people get online.

\section{Blending}

Blends are two words in which their non-morphemic components are mixed into one (O'Grady \& Guzman, 1997, p. 158). The beginning of a word is joined to the end of another word. A total of $19(8.3 \%)$ blends were found in the data. 8 (13.4\%) blends were detected in YM, 6 (9.4\%) in e-mail, and 5 (4.8\%) in FBK. Examples 
are the italicized items below.
(38) A: hi men whats up
B: I can c that u r online. (YM14)

Whats has been blended from "what" and "is". Other variants are the italicized items in the expressions: whatz up, wats up, wassup bro?

(39) A: thatz interesting, i like serious ple like u

B: please this is my number do get in ... (YM24)

Thatz is a blend from "that" and "is". An alternative of it is thats.

(40) A: ok i see, so how is ur dad

B: His fine

His is mixed together from "He" and "is". It is homophonous with the possessive adjective and pronoun his, and therefore could lead to confusion if the context is not well defined. The examples above are not the same as cliticization or contraction discussed earlier. With cliticization, an apostrophe is regularly employed to show missing letters or portions of the word(s). However, both blending and cliticization shorten the form of a word or a combination of words which is often used instead of the full form in informal situations. These could be cases of quick typing or attempts at limiting the expressions. Blends are similar to contextual elision in speech (Simo Bobda \& Mbangwana, 2004, pp. 82-83) where some sounds are dropped in the speech of most fast speakers.

\section{Slang}

Slang is a very informal language that is usually spoken rather than written, used especially by particular groups of people (mostly the young or powerless). YM has no slang words, FBK consists of 13 (17.4\%) and e-mail 3 (4.7\%). Spolsky (1998, p. 36) gave some features of slang: a jargon, rejection of formal rules, familiarizes a conversation. Factors, such as age, gender, and status, motivate the use of slang words. The extracts below contain some slang words that have been italicized.

(41) B: ...bro you just need to come and see them at night in a place call Domayo; you will shine your eyes with all sort of immoral activities.

A: Don't tell me you used to go njoka at night ... (FBK24)

Njoka means "enjoying at night"; it could be in a night clubs, bar, etc.

(42) just ngeme is copx me dats why I don't go 2facebk often. (E18)

Ngeme indicates "poverty". 
(43) A: am cool my dear, so [sic] what abt u, hp fine

B: im fine. how is bookwork and its wahalla ...

Wahalla signifies "problem/difficulty". The slang words are used among friends for intimacy and solidarity. Other slang words found in the data include gist (information, hint), ova java (too much enjoyment/relaxation), shomencam (joblessness), gars (friends, boys), and chap samtl (womanizer).

\section{Smileys or Emoticons}

A smiley or emoticon is a sideways image of a face formed by keyboard symbols, which is used in e-mails and other social media to express a particular emotion. It could be considered a word formation process in SM context because participants joke with language and employ novelties and unusual structures (cf. Hale \& Scanlon, 1999, p. 9). Furthermore, Page, Barton, Unger, and Zappavigna (2014) asserted that in SM context, "language should include image, sound, and kinetic resources found typically in digital interaction" (p. 27). They held that "meaning can be conveyed in spoken, written or signed forms or a combination of these" (p. 27). Figures from Table 2 show that the rate of occurrence of smileys is the lowest in the data (6.6\%). Specific details portray e-mail, FBK, and YM as having 3.2\%, $9.4 \%$, and 10\% respectively. This low occurrence could be due to the fact that Cameroonians are not yet very familiar with emoticons. Below are some examples from the data.

(44) did u see my best friend kaboko? ...

*B-) $\operatorname{cool}(\mathrm{E} 37)$

${ }^{*} B$-) expresses a wink, goodbye, and smiling face which implies warmth and humour. It shows that the sender is happy.

(45) will always keep in touch

Byeeeeeeeeee $\odot($ E11)

(-) displays "smile" or "happiness" and "goodbye" from the writer.

(46) A: what di u see

B: be careful

I took the photo just becos of ur

$D u \ldots . . m A^{* * * *}$

So be carefull. (FBK62)

Here, $D u \ldots . . m A^{* * * *}$ signifies heartiness or vigour.

The emoticons equally decorate the messages. Despite the fact that the frequency of occurrence of emoticons is low, it is still valuable because it is a word formation strategy that became popular with the advent of the Internet. It is the creative effort of users and it is expected that when Cameroonians will become more acquainted with online social interactions, they will use smileys more regularly. 


\section{Conclusion}

This study set out to investigate e-morphology in Cameroon SM with the aim of bringing out the morphological processes found in the data, finding out if the same methods of word formation emerge in the three data sets and the degree to which each is used. Analysis of Cameroon e-mail, FBK, and YM reveals the following word formation mechanisms: accent stylizations, clipping, borrowing, neologism, clitics, onomatopoeia, substitution of numbers for letters, abbreviations, compounding, conversion/inflection, reduplication, hybrid, blending, slang, and smileys. This gives a total of 15 word formation processes. The most desirable ways of forming words in all the three platforms are accent stylizations (77.4\%), clipping (66.53\%), and borrowing $(62.18 \%)$. Less frequent techniques of word formation are smileys $(6.6 \%)$, slang $(6.9 \%)$, and blending (8.3\%). Most of the word patterns are widely employed to condense information, save time, and ease communication. These findings are similar to earlier research (Berglund, 2009; Haas, 2011; Werry, 1996) where features like lexical repetition and substitution were discovered.

Factors, such as participants, the platform, and topic, determine the occurrence of these word formation methods and this brings in the idea of a continuum. In FBK, for example, there is the occurrence of all the 15 word formation methods and it tops the lead in almost all in terms of frequency of occurrence with $100 \%$ in borrowings, $92.46 \%$ in accent stylizations, $84 \%$ in clipping, $84 \%$ in neologisms, and $60 \%$ in clitics. It is only in the use of blending that YM leads with $13.4 \%$ as opposed to $4.8 \%$ for FBK. In addition, there is the absence of slang words in YM. There is equally the non-existence of acronyms in the e-mail data. The presence and the high frequencies of occurrence of the word formation processes in FBK are reminiscent of the fact that Cameroonian youths are keen on it as their preferred social media platform (see Tabe, 2017, p. 67). They have developed all types of word formation processes to communicate easily on it and there are indications that more e-morphological mechanisms will be developed as the number of Cameroonians using FBK continue to rise.

The word formation processes found in the data are established formal English word formation methods. However, they have been expanded and adjusted to suit the Cameroonian SM context. Crystal (2006, pp. 19-20) used the expression "netspeak" to describe features that are exclusive to the Internet. Some of the word formation processes found, such as smileys or emoticons, hybrid, substitution of numbers for letters, accent stylizations, and special repetition of letters, are more prevalent in Internet SM platforms than in other contexts. These outcomes of the Internet have become very fashionable not only in cyber culture, but also in mobile telephone short message services (see Feuba, 2009; Lyddy, Farina, Hanney, Farrell, \& O’Neill, 2014; Taiwo, 2012). Furthermore, even some distinctive English word formation processes adopted by cyber surfers have undergone a lot of modification and restructuring. This is the case of clippings. We find more shortenings than ever before for almost all kinds of structures. Words and sentences are clipped to letters. One can, therefore, say that the Internet has altered the scope of word formation processes in Cameroon SM and English language in general.

Facts gleaned from data analysis reveal that some borrowed nominal elements from CPE and home languages, such as ashia, bobolo, and clichi, appear to be specific to Cameroon. This is because most of the languages are used only in Cameroon and are evocative of the setting of the participants, their identity, and cultural values. This gives the English an indigenous flavour. In addition, Cameroonians adopt CamE sound system in the creation of their accent stylizations. This clear set of rules gives some Cameroonian peculiarities to this method of word formation. The morphological processes detected here are not reflexive of all the digital 
platforms used by Cameroonians. Those that are prestigious in these platforms like accent stylizations, clippings, and borrowings may not be found in other platforms, such as the ones used for distance learning. Additionally, the typical English word formation methods and those common in Internet social platforms could be found in other e-mails and chats elsewhere (Aslam, Ahmad, \& Sajid, 2011; Nirban, Sangwan, \& Rathore, 2011; Lee, 2007; Paolillo, 1999; Hentschel, 1998; Péter, 1998). Nevertheless, their modifications, restructuring, and frequencies of use may not be the same as those of Cameroonians.

\section{References}

Al-Khatib, M. A. (2008). E-mails as a model of communication among Jordanian University students: A sociolinguistic perspective. The International Journal of Language, Society and Culture, 25. Retrieved 15 June, 2010 from www.educ.utas.edu.au/users/tle/JOURNAL/

Anchimbe, E. A. (2010). Constructing a Diaspora Anglophone Cameroonian identity online. In R. Taiwo (Ed.), Handbook of research on discourse behavior and digital communication: Language structures and social interaction (pp. 130-144). Hershey, USA: IGI Global.

Anon. (n.d). A lexicon of New Orleans terminology and speech. The new orleans page/The gumbo pages. Retrieved 29 December, 2017 from http://gumbopages.com/yatspeak.html

Aslam, R. F. M., Ahmad, A., \& Sajid, M. A. (2011). A study of orthographic features of instant messaging in Pakistan: An empirical study. Language in India, 11. Retrieved 31 May, 2012 from www.languageinindia.com

Atechi, S. (2011). Is Cameroon pidgin flourishing or dying? An attempt to reconcile conflicting reports on the functions and status of Cameroon pidgin English. English Today, 27(3), 30-34.

Atud, D., Ambam, G., \& Ada, P. S. (2011). The influence of ICT on the written production of students in the English language: The case of lower and upper sixth students of Government Bilingual High School Maroua (Unpublished dissertation for a post-graduate diploma (DIPES II), ENS Maroua, The University of Maroua).

Baldwin, B. W. (1996). Conversations: Computer-mediated dialogue, multilogue and Learning (Dissertation, University of North Carolina).

Baron, N. S. (2002). Who sets e-mail style? Prescriptivism, coping strategies and democratising communication access. The Information Society, 18, 403-413.

Baron, N. S. (2003). Language of the Internet. In A. Farghali (Ed.), The Standford handbook for language engineers (pp. 59-127). Standford: CSLI Publications.

Barton, D., \& Lee, C. (2013). Language online: Investigating digital texts and practices. London \& New York: Routledge.

Behera, P., \& Muzaffar, S. (2015). The social media and democratic discourse: A critical discourse analysis of the power of 49 video. Asian Journal of Multidisciplinary Studies, 3(2), 155-161. Retrieved 2 January, 2018 from www.ajms.co.in

Belisle, R. (1996). E-mail activities in the ESL writing class. The Internet TESL Journal, 2(12). Retrieved 30 October, 2007 from http://iteslj.org/

Berglund, T. Ö. (2009). Disrupted turn adjacency and coherence maintenance in instant messaging conversations. Language@Internet, 6. Retrieved 14 May, 2011 from http://www.languageatinternet.de/articles/2009/2106

Berman, I. (2006). Email-“inspired” changes in non-native legal discourse. Language@Internet, 3. Retrieved 12 October, 2009 from http://www.languageatinternetde/articles/2006/372/index_html/

Biloa, E. (2004). Loans from European languages in African languages: Intercultural relationships and necessity. Retrieved 15 August, 2012 from http://www.inst.at/trans/15Nr/07_1/biloa15.htm

Brock, A., \& Seidel, B. (2002). Text types in computer-mediated communication-The case of discussion forums. In C. Todenhagen (Ed.), Text, text structure, text type. Festschrift for Wolfgang Thiele (pp. 13-28). Tübingen: Stauffenburg.

Crystal, D. (2005). The scope of Internet linguistics. Paper given online to the American association for the advancement of science, 18 February, 2005. Retrieved 4 July, 2011 from www.davidcrystal.com/DC_articles/Internet2.pdf

Crystal, D. (2006). Language and the Internet (2nd ed.). Cambridge: Cambridge University Press.

Davis, B. H., \& Brewer, J. (1997). Electronic discourse: Linguistic individuals in virtual space. New York, Albany: Suny Press.

Farina, F., \& Lyddy, F. (2011). The language of text messaging: "Linguistic Ruin" or resource? The Irish Psychologist, 37(6), 144-149. 
Ferrara, K., Brunner, H., \& Whittemore, G. (1991). Interactive written discourse as an emergent register. Written Communication, 8, 18-32.

Feuba, W. E. (2009). The sociolinguistics of mobile phone SMS usage in Cameroon and Nigeria. The International Journal of Language, Society and Culture, 28, 25-40. Retrieved 2 September, 2013 from www.educ.utas.edu.au/users/tle/JOURNAL/

Goodman, S. (1996). Market forces speak English. In S. Goodman and D. Graddol (Eds.), Redesigning English: New texts, new identities (pp. 141-180). London: The Open University Routledge.

Haas, C. (2011). Building and maintaining contexts in interactive networked writing: An examination of deixis and intertextuality in instant messaging. Journal of Business and Technical Communication, 25(3), 275-298.

Hale, C., \& Scanlon, J. (1999). Wired style: Principles of English usage in the digital age. New York: Broadway Books.

Haspelmath, M., \& Sims, A. D. (2010). Understanding morphology (2nd ed). London \& New York: Routledge.

Hentschel, E. (1998). Communication on IRC. Linguistics Online, 1. Retrieved 8 March, 2007 from http://www.linguistik-online.de/irc.htm

Herring, S. C. (1993). Gender and democracy in computer-mediated communication. The Electronic Journal of Communication, 3(4). Retrieved 23 June, 2011 from http://cios.org/EJCPUBLIC/003/2/00328.HTML

Herring, S. C. (1994). Gender differences in computer-mediated communication: Bringing familiar baggage to the new frontier. Keynote talk at American Library Association Annual Convention, Miami, Florida. Retrieved 30 January, 2011 from http://www.cpsr.org/cpsr/gender/herring.txt

Herring, S. C. (1996). Gender and ethics in computer-mediated communication. In C. Ess (Ed.), Philosophical perspectives on computer-mediated communication (pp. 115-145). Albany, New York: SUNY Press.

Herring, S. C. (1999). Interactional coherence in CMC. Journal of Computer Mediated Communication, 4(4). Retrieved 12 June, 2011 from http://www.ascusc.org/jcmc/vol4/issue4/herring.html

Herring, S. C. (2002). Computer-mediated communication on the Internet. Annual Review of Information Science and Technology, $36,109-168$.

Herring, S. C. (2011). Grammar and electronic communication. In C. A. Chapelle (Ed.), Encyclopedia of applied linguistics. Hoboken, NJ: Wiley-Blackwell. Retrieved 16 June, 2012 from http://ella.slis.indiana.edu/ herring/e-grammar.2011.pdf

Internet World Stats Newsletter. (2017). Miniwatts marketing group. Retrieved 4 January, 2018 from http://internetworldstats.com/stats $1 . h t m$

Johnpaul, O. N., \& Baba, D. D. (2016). The impact of netspeak abbreviations on effective communication among learners of English as a second language in Nigeria. Journal of the English Scholars Association of Nigeria (JESAN), 18(1), 36-43.

Kadir, Z. A., Maros, M., \& Hamid, B. A. (2012). Linguistic features in the online discussion forums. International Journal of Social Science and Humanity, 2(3), 276-281.

KhosraviNik, M. (2018). Social media critical discourse studies (SM-CDS). In J. Flowerdew and J. E. Richardson (Eds.), The Routledge handbook of critical discourse studies (pp. 582-596). London \& New York: Routledge.

Kouega, J. P., \& Somb Lingom, J. P. (2013). Non-official languages in the spoken media in Cameroon. In J. P. Kouega and A. A. Ayuk (Eds.), Globalisation and the frontiers of ethics: Critical essays on language and literature (pp. 19-37). Yaounde: Les Grandes Editions.

LAN, L. (2000). E-mail a challenge to Standard English? English Today 64, 16(4), 23-29, 55.

Lee, C. K. M. (2007). Text-making practices beyond the classroom context: Private instant messaging in Hong Kong. Computers and Composition, 2(3). 285-301.

Lewis, M. P., Gary, F. S., \& Charles, D. F. (Eds.). (2017). Ethnologue: Languages of the world (20th ed.). Dallas, Texas: SIL International. Retrieved 4 December, 2018 from http://www.ethnologue.com/ or http://www.ethnologue.com/country/CM

Lyddy, F., Farina, F., Hanney, J., Farrell, L., \& O’Neil, N. K. (2014). An analysis of language in university students' text messages. Journal of Computer-Mediated Communication, 19, 546-561. Retrieved 2 January, 2018 from http://onlinelibrary.wiley.com/doi/10.1111/jcc4.12045/epdf

Muniandy, A. V. A. (2003). Electronic-discourse (e-discourse): Spoken, written or a new hybrid? Prospect, 17(3), 45-68. Retrieved 5 May, 2011 from http: //www.nce/tr.mq.edu.au/prospect/17/pros17_3 avam.asp

Nagel, P. S. (1999). E-mail in the virtual ESL/EFL classroom. The Internet TESL Journal, 5(7). Retrieved 8 February, 2006 from http://iteslj.org/

Nformi, L. K. (2013). Email English of students of the University of Yaounde I (Unpublished dissertation for a post-graduate diploma (DIPES II), ENS Yaounde, The University of Yaounde I).

Ngefac, A. (2010). Linguistic choices in postcolonial multilingual Cameroon. Nordic Journal of African Studies, 19(3), 149-164. 
Nirban, V. S., Sangwan, D., \& Rathore, S. (2011). Language alterations in Internet relay chat discourse. IRACST-International Journal of Research in Management and Technology (IJRMT), 1(2), 93-96.

O'Grady, W., \& De Guzman, V. P. (1997). Morphology: The analysis of word structure. In W. O'Grady, M. Dobrovolsky, and F. Katamba (Eds.), Contemporary linguistics: An introduction (pp. 132-173). London: Longman.

Page, R., Barton, D., Unger, J. W., \& Zappavigna, M. (2014). Researching language and social media: A student guide. London \& New York: Routledge.

Paolillo, J. C. (1996). Language choice on soc.culture.punjab. In S. Herring (Ed.), Special issue on computer-mediated discourse analysis. The Electronic Journal of Communication, 6(3). Retrieved 12 August, 2007 from http://www.cios.org/www/ejcmain.html

Paolillo, J. C. (1999). The virtual speech community: Social network and language variation on IRC. Journal of Computer-Mediated Communication, 4(4). Retrieved 12 August, 2007 from http://www.ascusc.org/jcmc/vol4/issue4/paolillo.html

Paolillo, J. C. (2001). Language variation on Internet Relay Chat: A social network approach. Journal of Sociolinguistics, 5, $180-213$.

Péter, G. (1998). The IRC vernacular: A linguistic study of Internet Relay Chat (Thesis, incomplete version available online at http://gelleri.weebly.com/the-irc-vernacular.html).

Petryshyn, K. (2014). English loanwords in electronic media discourse in Ukraine (Master thesis presented to the Department of Literature, Area Studies and European Language, University of Oslo).

Posteguillo, S. (2002). Netlinguistics and English for Internet purposes. Ibérica, 4, 21-38. Retrieved 22 October, 2010 from www.aelfe.org/documents/text4-posteguillo.pdf

Renouf, A. (2007). Tracing lexical productivity and creativity in the British media: "The chavs and the chav-nots". In J. Munat (Ed.), Lexical creativity, texts and contexts (pp. 61-89). Amsterdam: John Benjamins.

Ronkin, M., \& Helen, E. K. (1999). Mock Ebonics: Linguistic racism in parodies of Ebonics on the Internet. Journal of Sociolinguistics, 3(3), 360-380.

Schneider, E. W. (2008). Towards endonormativity? African English and the dynamic model of the evolution of postcolonial Englishes. In K. Harrow and K. Mpoche (Eds.), Language, literature and education in multicultural societies: Collaborative research on Africa (pp. 283-305). Newcastle: Cambridge Scholars Publishing.

Simo Bobda, A. (2001). Taming the madness of English. Modern English Teacher, 10(2), 11-17.

Simo Bobda, A., \& Mbangwana, P. (2004). An introduction to English speech. Yaounde: B \& K Language Institute.

Spolsky, B. (1998). Sociolinguistics. Oxford: Oxford University Press.

Tabe, C. A. (2004). Electronic discourse: A comparative study of some Cameroonian and British e-mail messages (Unpublished DEA dissertation, The University of Yaounde 1).

Tabe, C. A. (2008). Orality and literacy in Cameroon e-mail discourse. In K. Harrow and K. Mpoche (Eds.), Language, literature and education in multicultural societies: Collaborative research on Africa (pp. 194-209). Newcastle: Cambridge Scholars Publishing.

Tabe, C. A. (2011). A study of e-mail messages in Cameroon English (Unpublished Ph.D. thesis, The University of Yaounde I, Cameroon).

Tabe, C. A. (2012). Discourse features in Cameroon Internet Relay Chat (IRC). KALIAO, 4(8), 219-230.

Tabe, C. A. (2013a). The integration and use of ICT tools for English language instruction in Cameroon: Assessing challenges and evaluating benefits. Syllabus Review, Human \& Social Sci. Ser. 4(1), 79-99. Retrieved 13 July, 2013 from http://www.ens.cm/spip.php?article652

Tabe, C. A. (2013b). E-sentence in Cameroon Internet Relay Chat (IRC). In J. P. Kouega and A. A. Ayuk (Eds.), Globalisation and the frontiers of ethics: Critical essays on language and literature (pp. 39-57). Yaounde: Les Grandes Editions.

Tabe, C. A. (2016). Language and humour in Cameroon social media. In R. Taiwo, A. Odebunmi, and A. Adetunji (Eds.), Analyzing language and humor in online communication (pp. 131-163). Hershey, PA: IGI Global. Retrieved from http://www.igi-global.com/viewtitle.aspx?TitleId=156882

Tabe, C. A. (2017). Multilingualism in Cameroon social media. In L. M. Meutem Kamtchueng and P. L. King Ebéhédi (Eds.), Multilingualism as a model: Fifty-four years of coexistence of English and French with native languages in Cameroon (pp. 59-87). Frankfurt: Peter Lang.

Tagliamonte, S. A., \& Denis, D. (2008). Linguistic ruin? LOL! Instant messaging and teen language. American Speech, 83(1). Retrieved 31 May, 2012 from http://web.uvic.ca/ling/coursework/ling395/395_LOL.pdf 
Taiwo, R. (2012). Language and mobile telecommunication in Nigeria: SMS as a digital lingual-cultural expression. Ile-Ife, Nigeria: Obafemi Awolowo University Press.

Werry, C. C. (1996). Linguistic and interactional features of Internet relay chat. In S. Herring (Ed.), Computer-mediated communication: Linguistic, social and cross-cultural perspectives (pp. 47-63). Philadelphia: John Benjamins.

Zappavigna, M. (2012). Discourse of Twitter and social media: How we use language to create affiliation on the Web. London \& New York: Continuum. 
Appendix

Table 1

Corpus Composition

\begin{tabular}{|l|l|l|l|l|}
\hline & E-mail & Facebook & Yahoo Messenger \\
\hline Year(s) of data collection & $2014-2017$ & $2015-2017$ & $2012-2016$ & Total \\
\hline Participants & $\begin{array}{l}\text { Randomly selected } \\
\text { Cameroonians of all fields }\end{array}$ & $\begin{array}{l}\text { Randomly selected } \\
\text { Cameroonians }\end{array}$ & $\begin{array}{l}\text { Adm. Tech. \& Acc. Level 4 } \\
\text { students of ENSET Douala }\end{array}$ & 60 \\
\hline Data used & 64 & 106 & 60 & 230 \\
\hline
\end{tabular}

Table 2

Types of E-morphological Processes and Their General Distribution in Cameroon E-mail, FBK and YM

\begin{tabular}{|c|c|c|c|c|c|c|c|c|c|c|c|c|c|c|c|}
\hline $\begin{array}{l}\text { Nature } \\
\text { Text type }\end{array}$ & $\begin{array}{l}\text { Accent } \\
\text { styls }\end{array}$ & Clipping & Borrowing & $\begin{array}{l}\text { Neolo-gism } \\
\mathrm{s}\end{array}$ & Clitics & $\begin{array}{l}\text { Onoma- } \\
\text { topoeia }\end{array}$ & $\begin{array}{l}\text { Substi-tut } \\
\text { ion }\end{array}$ & $\begin{array}{l}\text { Abbrevia } \\
\text { tions }\end{array}$ & $\begin{array}{l}\text { Compoun } \\
\text { ding }\end{array} \mid$ & $\begin{array}{l}\text { Conversion } \\
\text { /Inflection }\end{array}$ & $\begin{array}{l}\text { Reduplica } \\
\text {-tion }\end{array}$ & Hybrid & Blending & Slang & Smileys \\
\hline E-mail & $\begin{array}{l}51 * * \\
(79.7 \%)\end{array}$ & $\left|\begin{array}{l}43 * * \\
(67.2 \%)\end{array}\right|$ & $\begin{array}{l}23 \\
(35.9 \%)\end{array}$ & $\begin{array}{l}16^{*} \\
(25 \%)\end{array}$ & \begin{tabular}{|l|}
28 \\
$(43.8$ \\
$\%)$ \\
\end{tabular} & $\mid \begin{array}{l}07 \\
(10.9 \%)\end{array}$ & $\begin{array}{l}24 * \\
(37.5 \%)\end{array}$ & $\begin{array}{l}04 \\
(6.3 \%)\end{array}$ & $\begin{array}{l}15 \\
(23.5 \%)\end{array}$ & $\begin{array}{l}03 \\
(4.7 \%)\end{array}$ & $\begin{array}{l}03 \\
(4.7 \%)\end{array}$ & $\begin{array}{l}11 * \\
(17.2 \%)\end{array}$ & $\begin{array}{l}06 \\
(9.4 \%)\end{array}$ & $\begin{array}{l}03 \\
(4.7 \%)\end{array}$ & $\begin{array}{l}02 \\
(3.2 \%)\end{array}$ \\
\hline Facebook & $\begin{array}{l}98 * * \\
(92.5)\end{array}$ & $\begin{array}{l}63 * * \\
(84 \%)\end{array}$ & $\begin{array}{l}106^{*} \\
(100 \%)\end{array}$ & $\begin{array}{l}63^{*} \\
(84 \%)\end{array}$ & $\begin{array}{l}45^{*} \\
(60 \%)\end{array}$ & \begin{tabular}{|l}
51 \\
$(48.2 \%)$
\end{tabular} & \begin{tabular}{|l|}
$31 *$ \\
$(41.4 \%)$
\end{tabular} & \begin{tabular}{|l}
35 \\
$(33.1 \%)$
\end{tabular} & $\begin{array}{l}20 \\
(18.9 \%)\end{array}$ & $\begin{array}{l}20 \\
(26.7 \%)\end{array}$ & \begin{tabular}{|l|}
20 \\
$(26.7 \%)$
\end{tabular} & \begin{tabular}{|l|}
15 \\
$(14.2 \%)$
\end{tabular} & $\begin{array}{l}05 \\
(4.8 \%)\end{array}$ & $\begin{array}{l}13 \\
(17.4 \%)\end{array}$ & $\begin{array}{l}07 \\
(9.4 \%) \\
\end{array}$ \\
\hline YM & $\begin{array}{l}29 \\
(48.4) \\
\end{array}$ & \begin{tabular}{|l|}
$47 *$ \\
$(78.4 \%)$ \\
\end{tabular} & \begin{tabular}{|l|}
14 \\
$(23.4 \%)$ \\
\end{tabular} & \begin{tabular}{|l|l}
$40 *$ \\
$(66.7 \%)$
\end{tabular} & $\begin{array}{l}30 \\
(50 \%) \\
\end{array}$ & \begin{tabular}{|l|}
28 \\
$(46.7 \%)$ \\
\end{tabular} & \begin{tabular}{|l|}
20 \\
$(33.4 \%)$ \\
\end{tabular} & $\begin{array}{l}25 \\
(41.7 \%) \\
\end{array}$ & \begin{tabular}{|l}
08 \\
$(13.4 \%)$ \\
\end{tabular} & $\begin{array}{l}10 \\
(16.7 \%) \\
\end{array}$ & \begin{tabular}{|l}
08 \\
$(13.4 \%)$ \\
\end{tabular} & $\begin{array}{l}02 \\
(3.4 \%) \\
\end{array}$ & \begin{tabular}{|l|l}
08 \\
$(13.4 \%)$
\end{tabular} & 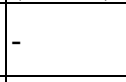 & $\begin{array}{l}06 \\
(10 \%) \\
\end{array}$ \\
\hline Total & $\begin{array}{l}178 \\
(77.4 \%)\end{array}$ & $\begin{array}{l}153 \\
(66.6 \%)\end{array}$ & $\mid \begin{array}{l}143 \\
(62.2 \%)\end{array}$ & $\begin{array}{l}119 \\
(51.8 \%)\end{array}$ & $\begin{array}{l}103 \\
(44.8 \\
\%) \\
\end{array}$ & $\begin{array}{l}86 \\
(37.4 \%)\end{array}$ & $\begin{array}{l}75 \\
(32.6 \%)\end{array}$ & $\begin{array}{l}64 \\
(27.9 \%)\end{array}$ & $\begin{array}{l}43 \\
(18.7 \%)\end{array}$ & $\begin{array}{l}33 \\
(14.6 \%)\end{array}$ & $\begin{array}{l}31 \\
(13.5 \%)\end{array}$ & $\begin{array}{l}28 \\
(12.2 \%)\end{array}$ & $\begin{array}{l}19 \\
(8.3 \%)\end{array}$ & $\begin{array}{l}16 \\
(6.9 \%)\end{array}$ & $\begin{array}{l}15 \\
(6.6 \%)\end{array}$ \\
\hline
\end{tabular}

Notes. Accent styls: Accent stylizations; Numbers with one asterisk indicate high frequency of occurrence in each of the e-mails/chats in which it is found; Numbers with two asterisks indicate most high frequency of occurrence in each of the e-mails/chats.

Table 3

Additional Lexical Creativity for Some Internet-Related Words

\begin{tabular}{|l|l|l|l|}
\hline E-mail & Facebook & Chat & Post (via Internet) \\
\hline e-mailed (verb) & facebook stuff (noun) & chatting (verb) & will post (verb) \\
\hline e-mail address (noun) & facebook password (noun) & chatted (verb) & to post link (verb) \\
\hline \multirow{2}{*}{ e-mail information (noun) } & facebook account (noun) & to chat/to video chat (verb) & posted (verb) \\
\cline { 3 - 4 } & & e-chat (noun) & \\
\hline
\end{tabular}

